\title{
CRYOPUMPING FIELD JOINT CAN TESTING
}

\author{
W.L. Johnson ${ }^{1}$, J. E. Fesmire ${ }^{1}$, and B. E. Meneghelli ${ }^{2}$ \\ ${ }^{1}$ NASA Kennedy Space Center, NE-F6 \\ Kennedy Space Center, FL, 32899, USA \\ ${ }^{2}$ ASRC Aerospace \\ Kennedy Space Center, FL, 32899, USA
}

\begin{abstract}
For long installations, vacuum jacketed piping often comes in 40 foot sections that are butt welded together in the field. A short can is then welded over the bare pipe connection to allow for insulation to be protected from the environment. Traditionally, the field joint is insulated with multilayer insulation and a vacuum is pulled on the can to minimize heat leak through the bare section and prevent frost from forming on the pipe section. The vacuum jacketed lines for the Ares I mobile launch platform were to be a combined 2000 feet long, with 60+ pipe sections and field joint cans. Historically, Kennedy Space Center has drilled a hole in the long sections to create a common vacuum with the field joint can to minimize maintenance on the vacuum jacketed piping. However, this effort looked at ways to use a passive system that didn't require a vacuum, but may cryopump to create its own vacuum. Various forms of aerogel, multilayer insulations, and combinations thereof were tested to determine the best method of insulating the field joint while minimizing maintenance and thermal losses.
\end{abstract}

KEYWORDS: Thermal insulation, Aerogel

\section{INTRODUCTION}

In the process of loading propellant tanks for a launch vehicle, large quantities of propellant flow through vacuum jacketed piping for short durations of time. The piping is made in roughly 40 foot sections with weld joints on each end. The welds are made in the field as it would be too hard to fabricate the system elsewhere and then move the large piping to the launch pad. When NASA's launch pads were built in the mid-1960s, an atmospheric pressure insulation system was used on the welded joints, however, the complicated structural/thermal support between the inner and outer pipes of the vacuum 
jacketed sections had many feet of butt weld per end and frequent issues with vacuum retention occurred. The easiest solution at the time was to drill holes into each vacuum jacket section to make it common. with the field joint and weld a can around the field joint. To minimize heat load on the weld joint, it is wrapped in multilayer insulation (MLI) and the can is welded over the joint to allow a vacuum to be pulled on the MLI. Modern field joint cans do not have a common vacuum with the pipes they connect; however that requires twice as many vacuum pumpout ports. KSC ground operations is required to check each pump out port every 30 days, thus doubling the number of pump out ports would raise the maintenance costs of the piping considerably.

Aerogel beads and blankets are highly nanoporous materials with specific surface

areas over $1000 \mathrm{~m}^{2} / \mathrm{g}$. Past testing at the Cryogenics Test Laboratory has shown that they are highly absorptive, soaking up nearly $70 \%$ by volume of liquid nitrogen. [1,2] Additionally, it has been shown that these aerogel materials eventually come to a steady state where no more sorption is occurring. Past application of these novel material properties have focused on preventing pools of cryogenic liquids from forming within launch vehicles [2], but now a new application encouraging the cryopumping is analyzed within field joint cans for vacuum jacketed piping.

To test several ideas of replace the current common vacuum while still minimizing maintenance on the sections, a test article was built to simulate a 4 " inner pipe by 6" outer pipe vacuum jacketed line. The field joint tested is a standard industry design with conical sections manufactured by Eden Cryogenics. Carbon dioxide was used as the purge gas as this would allow atmospheric operation most of the time while drastically reducing the pressure when the lines were chilled down with liquid nitrogen (liquid oxygen or liquid hydrogen in the actual case).

\section{EXPERIMENT}

A test article was built to simulate the field can around two joined pieces of piping. Eight type-E thermocouples were installed around the test article, with three inside the vacuum can while the vacuum pressure inside the can was measured by MKS Baratron capacitance manometers. FIGURE 1 shows the test article thermocouple layout as well as the test article installed in the lab for testing. Inside the vacuum can, T1 measured the temperature at the weld joint, $\mathrm{T} 2$ measured the temperature half way up the cone connecting the inner and outer pipes, and T3 measured the warm boundary temperature of the insulation. Outside of the test article, T4 and T5 measured the can exterior temperature, T6 and T8 measured the cone junction temperatures on the outer pipe weld, and T7 measured the skin temperature of one of the simulated pipes. Liquid nitrogen was used to chill down the system and provide a constant cold boundary temperature for the entire system. The cap and dryer duct were attached to the test article to prevent the cold nitrogen boil-off from flowing down the side of the test article and artificially chilling it.

Several different insulations as well as vacuum levels were tested. Initial testing consisted of testing MLI at high vacuum to represent the state of the art and current configuration at Kennedy Space Center. Following that several forms of layered composite insulation (LCI) and aerogel were tested to determine the level of cryopumping provided in the actual configuration using carbon dioxide (CO2) as the purge gas. The first LCI (Tests 3 and 4) involved an aerogel blanket on the cold mass, several layers of MLI outside of that, followed by another aerogel blanket and several more layers of MLI. For test 4, aerogel beads were blown in to completely fill the can cavity. For test 5, the MLI was 
removed from between the aerogel blankets. Test 6 and 7 used the same aerogel blankets with the plastic backing removed with test 7 having the aerogel beads blown in again.

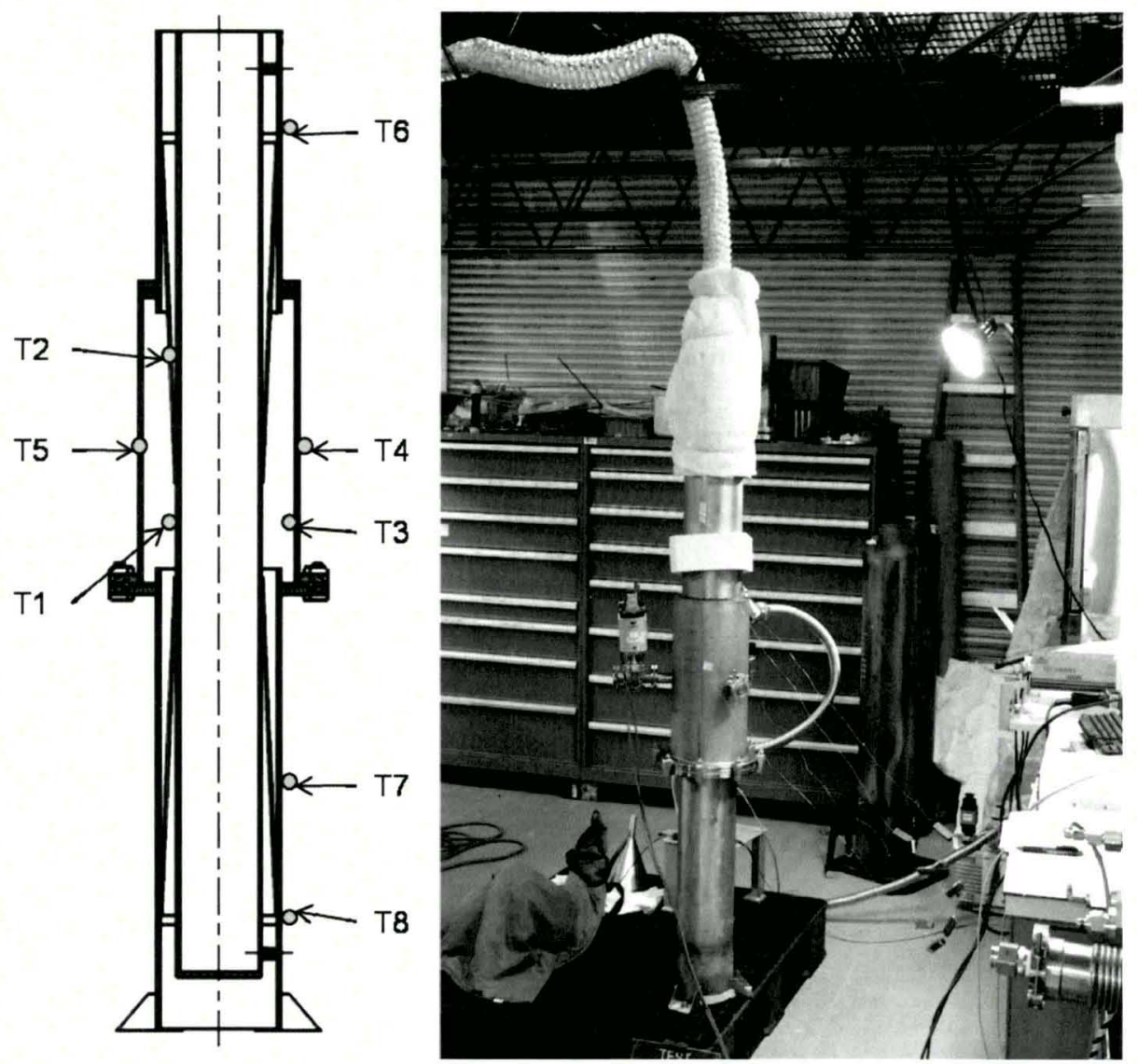

FIGURE 1: Field Joint Test Article with thermocouple layout and the lab test configuration

Test 8 was the same as test 7 except that the can was maintained at ambient pressure to simulate a vacuum leak. Test 9 was the same as test 6 run at ambient pressure to simulate a vacuum leak.

The test procedure involved applying the insulation inside the vacuum can, then sealing up the can to prevent vacuum leaks. Once the can was sealed, a vacuum was pulled to below 100 millitorr and back-filled with CO2. For the high vacuum MLI testing, the can was pumped to below 1 millitorr. Liquid nitrogen was then used to fill the inner pipe and chill the system down. The nitrogen was refilled multiple times during the test at roughly one hour intervals to maintain the chilled conditions on the inner pipe. The thermocouples and pressure sensors were monitored for the duration of testing.

\section{HEAT LOAD ANALYSIS ON A REAL SYSTEM}

An analysis was done on the heat load of the entire pipe joint system. The inner and outer pipes are held together by conical connector which must be accounted for in addition to the insulation over the roughly 6" bare section of pipe (also much include bare pipe underneath the extended heat path structural joint and bare extended heat path structural joint). Even though the bare pipe section may only be 6", the field can itself is on the order of 18 ", thus there are 12 " of length of pipe that are nearly impossible to insulate due to the structural interference. For a 8" by 10 " vacuum jacketed closeout, the structural heat load along the two conical sections is roughly $14.6 \mathrm{~W}$, whereas Eden calculations reveal a total 
heat load of 17.3 , thus $2.7 \mathrm{~W}$ are attributed to the insulation (generally MLI at HV). For 200 feet of piping split up into 5 sections of 40 feet, the spec heat load is $0.7 \mathrm{~W} / \mathrm{ft}$ for a total of $140 \mathrm{~W}$. Meanwhile the 4 field joints at $17 \mathrm{~W}$ each, contribute $68 \mathrm{~W}$, for a total system heat load of $208 \mathrm{~W}$. Nearly $1 / 3^{\text {rd }}$ of the heat load comes from the 4 joints. For the 6 inches of bare pipe, filling the volume with aerogel insulation at no vacuum (760 torr) yields a heat load of $5 \mathrm{~W}$. That same insulation at soft vacuum (1 Torr) has a heat load of $2.5 \mathrm{~W}$; and at high vacuum the heat load is $0.5 \mathrm{~W}$. Thus allowing back filling with a cryopumping gas such as carbon dioxide that will stabilize well below 1 Torr when cold would produce a system with roughly the same heat load as the MLI at high vacuum. Further, aerogel is an isotropic material unlike MLI and can be used to fill the entire volume including around the conical structural supports and reduce the total system load.

\section{RESULTS AND DISCUSSION}

The results showing the minimum cryopumping pressure achieved are shown in FIGURE 2. The pressures show the extent of the cryopuming of the $\mathrm{CO} 2$ gas into the nanoporous aerogel structure. The field joint can skin temperatures are shown in FIGURE 3. By assuming that the laboratory room was fairly constant in both temperature and natural convection currents, the skin temperature shows the relative comparison of heat load through the insulation system. Tests with a higher skin temperature are better insulation systems than those with lower skin temperatures. The laboratory room where the testing took place is maintained at approximately $295 \mathrm{~K}$. During Test 6 , the laboratory door was left open in the middle of the summer and thus the ambient temperature was much higher than the other tests, accounting for the out of family temperature in FIGURE 3.

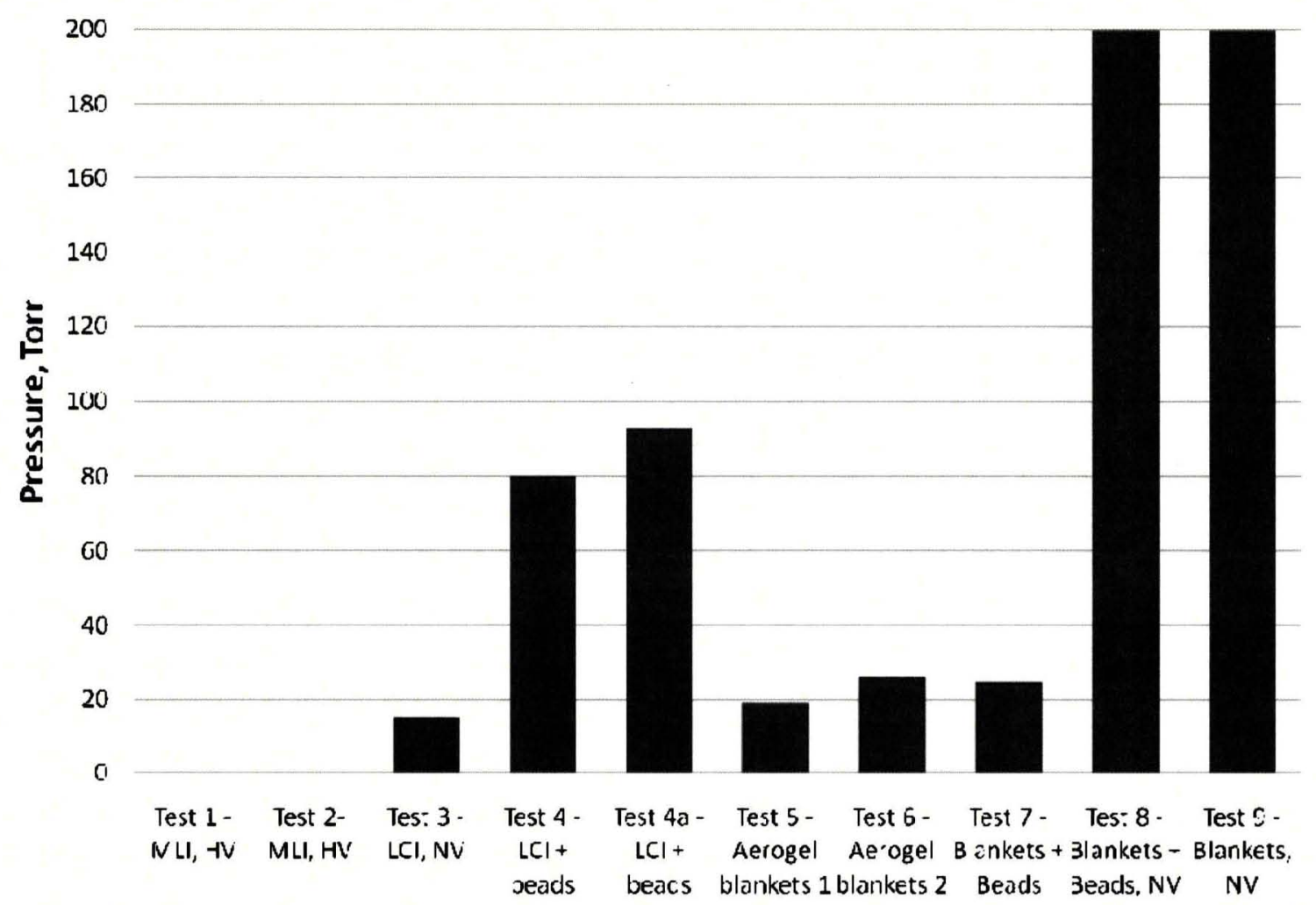

FIGURE 2: Minimum can pressure from cryopumping. Test 1 and 2 were conducted at high vacuum and tests 8 and 9 were conducted at 760 torr (ambient pressure). 


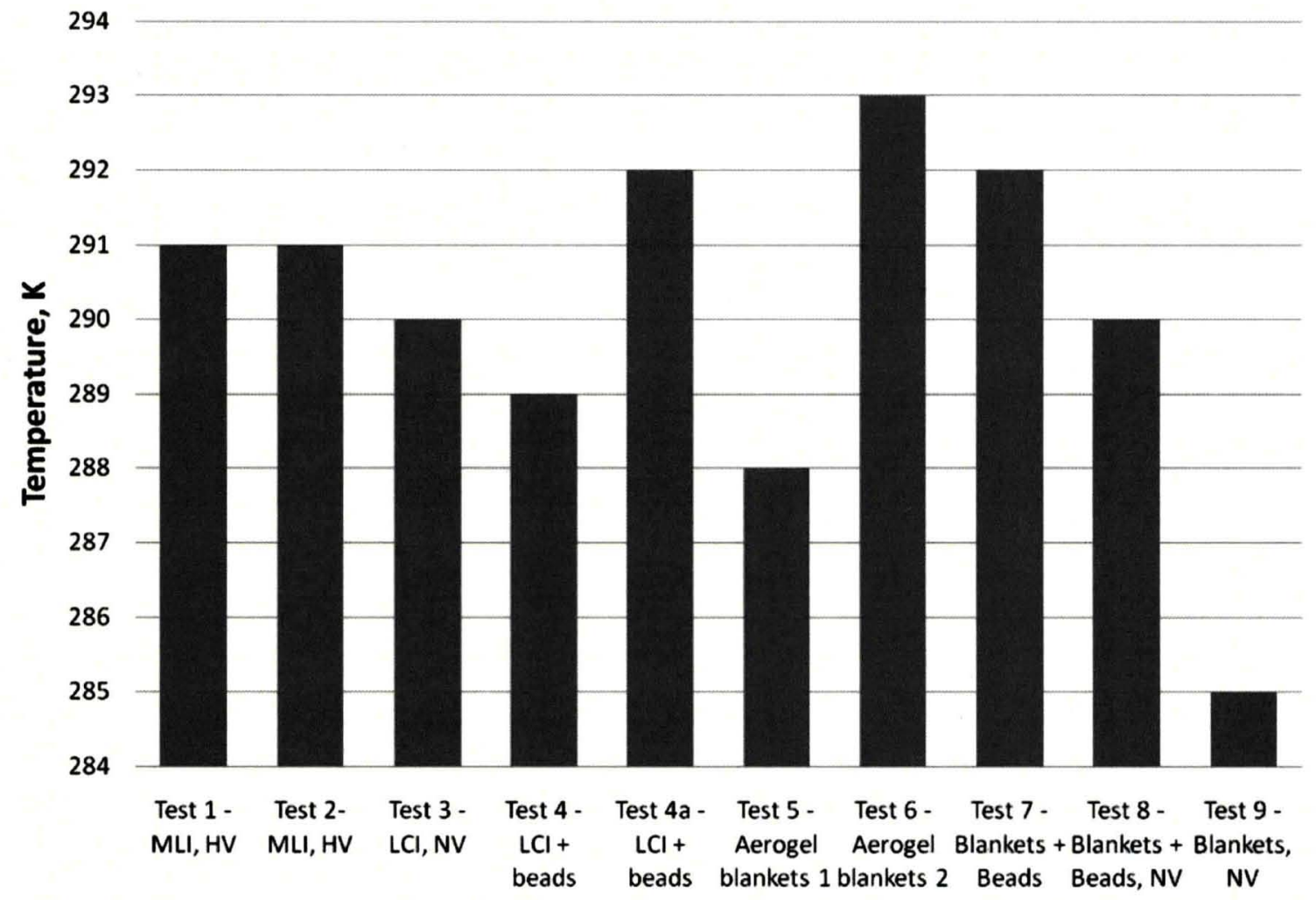

FIGURE 3: Field joint vacuum can skin temperature, T5.

The pressure data indicates that that all of the systems cryopumped rather well, achieving pressures below 20 torr in several instances. It is noted that the aerogel systems pumped much better without the MLI blankets present. While the aerogel insulation systems did not pump below 1 Torr, the performance still equaled or exceeded the MLI based insulation systems.

The temperatures show that when the beads are back-filled into the systems filling the entire can, the performance is better than even the MLI at high vacuum (due to the much increased thickness of the insulation system). Even if no cryopumping is achieved (Test 8), the thermal performance of the system is relatively similar to the MLI at high vacuum. FIGURE 4 shows the typical data from the system. 


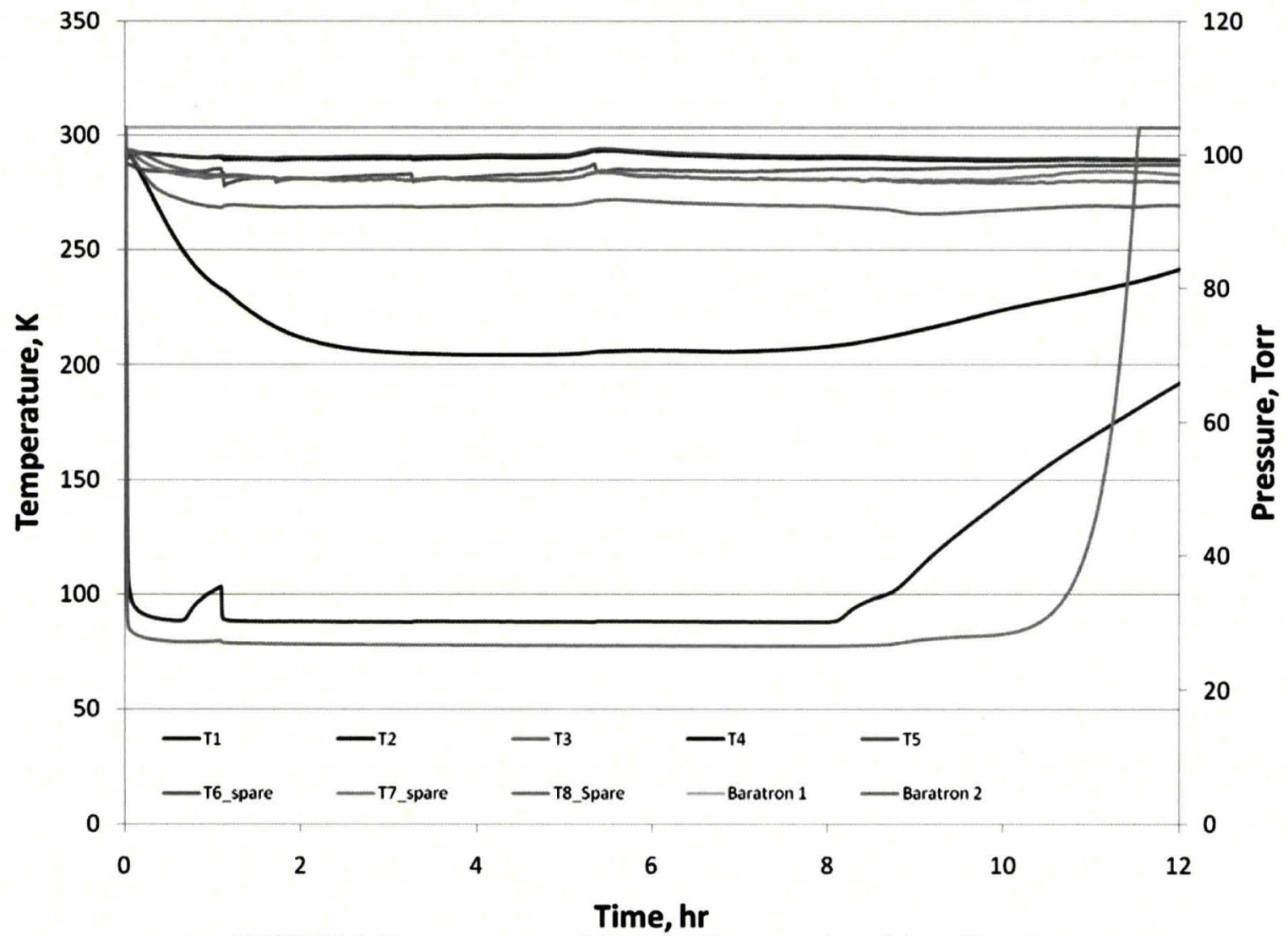

FIGURE 4: Temperatures and Vacuum Pressure plotted from Test 6

\section{CONCLUSIONS}

A series of experiments were run at the Cryogenic Test Laboratory to determine the best way to insulate a vacuum jacketed transfer line field joint system. The main issues to be considered are the minimization of maintenance requirements as well as the best performing system for both the transfer lines and the field joint cans. A four inch by six inch vacuum jacketed pipeline test apparatus with an eight inch joint can was developed to test the various insulation systems. The testing showed that using a combination of aerogel blankets and aerogel beads with a residual gas of $\mathrm{CO} 2$ appears to be the best performing non-vacuum system. By eliminating the high vacuum requirements, monthly pressure readings don't have to be taken, yet the vacuums achieved in the manufacturers plant are not compromised either.

\section{ACKNOWLEDGEMENTS}

The authors would like to acknowledge Mr. Adam Swanger, Mr. Manny Magala, and Ms. Amber Porter for their help in performing the testing.

\section{REFERENCES}

1. Johnson, W.L. "Sorption of Liquid Nitrogen" presented at the AIAA Southeast Regional Student Conference, Starkville, MS, April 2006.

2. Fesmire, J.E. and Sass, J.P. Cryogenics 48, pp. 223-231 (2008) 